\title{
Conceito Antropofagia: vanguarda e proliferação ${ }^{1}$
}

Francine Regis Goudel ${ }^{2}$

\section{Resumo}

Este artigo configura-se em uma análise da busca do caráter do projeto estético nacional nas vanguardas brasileiras, especialmente do início da arte moderna no Brasil com a semana de 1922. Parte do conceito da Antropofagia, idealizado em 1928 no manifesto antropofágico escrito por Oswald de Andrade, para entender a questão de assimilação e repulsa que engloba a arte de vanguarda brasileira; trazendo assim uma reflexão sobre a legitimidade dessa arte e a legitimidade da arte produzida no país ainda hoje.

Palavras-chave: Antropofagia brasileira, Semana de Arte 22, Raízes do Brasil, Vanguardas brasileiras.

"Só a antropofagia nos une. Socialmente. Economicamente. Filosoficamente." Assim inicia-se o Manifesto Antropófago escrito por Oswald de Andrade em $1^{\circ}$ de maio de 1928, um vanguardista brasileiro, ensaísta e dramaturgo, tido na época como apenas um jovem intelectual filho da burguesia agrária paulistana. Publicado no primeiro número da Revista de Antropofagia do Diário de São Paulo, Oswald defendia em linhas escritas inteligentemente nocivas e com uma pitada de sarcasmo, a síntese das idéias ainda em voga pelos "modernos" de uma arte brasileira autônoma com caráter nacionalista - ainda que seis anos mais tarde da acontecida primeira semana de arte moderna que chacoalhou o circuito cultural do país.

O conceito antropofágico reavivado para ser discutido na criação do caráter nacional da arte moderna brasileira vem à tona para delimitar a vontade de reconstruir os cacos de uma nação feita em retalhos e dar voz a quem só soube até então ecoar; conceito este que ao longo de quatro séculos havia se tornado um elemento embargado tanto no discurso "culto" do país, quanto dentro da própria cultura indígena, voltando como abre alas do pensamento da

1 Título do artigo de pesquisa desenvolvido juntamente com o projeto:

Raízes Antropofágicas: labirintos e paradoxos na constituição formativa do modernismo brasileiro, coordenado pela Prof ${ }^{a}$. Dra . Marta Martins.

2 Acadêmica do curso de Artes Plásticas com habilitação em Licenciatura - DAP / UDESC, bolsista de iniciação científica do PROBIC / CNPq, com orientação da Prof ${ }^{a}$. Dr ${ }^{a}$. Marta Martins do Departamento de Artes Plásticas -DAP- do Centro de Artes da Universidade do Estado de Santa Catarina CEART-UDESC. 
primeira manifestação vanguardista brasileira em arte, na avidez com a qual todo objeto reprimido retorna. Tal conceito subsidia o entendimento de um momento cultural onde os artistas e intelectuais brasileiros estão focados em uma mudança na produção artística vigente, que de acordo com essa vontade deveria romper com a tradição acadêmica importada das vanguardas européias e elucidar uma volta à apreensão da cultura popular do nosso próprio país utilizando-a como temática, o que se encontra estritamente relacionada ao projeto estético de uma arte à brasileira.

Perguntei a um homem o que era Direito. Ele me respondeu que era a garantia do exercício da possibilidade. Esse homem chamava-se Galli Matias. Comi-o. (...) Contra as sublimações antagônicas. Trazidas nas caravelas. (...) Mas não foram cruzados que vieram. Foram fugitivos de uma civilização que estamos comendo, porque somos fortes e vingativos como o Jabuti. [Trecho do Manifesto Antropófago de Oswald de Andrade]

A palavra Antropofagia evoca desse modo toda uma idéia trazida das raízes brasileiras do parente índio, a cerimônia de apropriação do outro, uma não submissão, um introduzi-lo e degluti-lo. Sabe-se que o ritual Antropofágico faz parte da idéia de apropriação do outro, "comer" o inimigo para dele abastar-se, assimilar o Outro para dele aproveitar suas virtudes, e nesse sentido, os modernistas foram pontuais na valorização desse conceito e criam a problemática da Antropofagia no sentido da assimilação da arte que vem das vanguardas européias ${ }^{3}$, propondo absorvê-la e recriá-la, não na acepção de "engoli-la" e reproduzi-la. Era essa a chave da idéia modernista na semana de 22 , embutir em nosso país uma "nova" maneira do fazer arte; era a concepção de encarar, conhecer e recriar que gostariam que se mantivesse nos trabalhos produzidos por quem representava a cena da vanguarda brasileira.

Despojado e defensor ferrenho de suas idéias, Oswald de Andrade em companhia de seus amigos também ativos no circuito cultural vigente, acreditava na mudança da arte brasileira, (até então permeada por produções acadêmicas) sabia exatamente o que estava manifestando. Oswald construiu nas frases do Manifesto Antropófago a catarse do processamento da própria nacionalidade, uma nova leitura da história do Brasil que parte da

3 Não só da vanguarda européia, pois no momento cultural artístico do inicio do século XX, mais exatamente em meados da década de 1930, os Estados Unidos começava a mostrar sua força artística com os ideais manifestados pelo então crítico americano Clement Greenberg. 
deglutição do bispo Pero Fernandes Sardinha $^{4}$ e finaliza cem anos após o pedido de independência escrevendo ao final do manifesto: "A nossa independência ainda não foi proclamada." 5 .

A vontade por parte dos intelectuais brasileiros da época de reconstruir a história das raízes do Brasil era tão intensa que outros autores, como Sérgio Buarque de Holanda e Mario de Andrade manifestaram-se na busca de descobrir o que mais cabia a identidade nacional.

Sérgio Buarque de Holanda parte de uma vertente historiográfica e social para escrever em 1936 Raízes do Brasil, um tratado sobre a cultura do povo brasileiro, uma obra que busca entender as raízes que caracterizam nossa cultura nacional. Em seu livro destaca a preocupação de compreender a formação da cultura brasileira analisando nossa herança colonial, conceituando as relações de afetividade que rondam o homem que aqui vive aos olhos dos outros povos, buscando definir o Brasil, o brasileiro e a identidade desse povo, que como o próprio autor manifesta na página inicial do livro, acredita ser ainda um povo desterrado em sua própria terra.

Holanda postula diversas reflexões sobre o homem brasileiro e sua identidade nacional, parte de tipos contrapostos esboçados pelas figuras do semeador e o ladrilhador, o anglo saxônio e o ibérico, o espanhol e o português, para concluir no "Homem Cordial", utilizando assim dessas figuras para formular com a idéia da cordialidade o modo de sociabilidade brasileira. O "Homem Cordial” para o autor é a expressão feliz, a contribuição brasileira para a civilização $o^{6}$, sendo então uma espécie de palavra-conceito para denominar o modo de vida e relação que caracteriza esse homem brasileiro.

No domínio da lingüística, para citar um exemplo, esse modo de ser parece refletir-se em nosso pendor acentuado para o emprego dos diminutivos. A terminação "inho", aposta às palavras, serve para nos familiarizar mais com as pessoas ou os objetos e, ao mesmo tempo, para lhes dar relevo. É a maneira de fazê-los mais acessíveis aos sentidos e também de aproximá-los do coração. [HOLANDA, 2006, p.148]

\footnotetext{
4 "Bispo Pero Fernandes Sardinha (? - 1556). Sacerdote português, foi o primeiro bispo do Brasil. Ao naufragar no litoral de Alagoas, ele foi morto (num ritual antropofágico) pelos índios Caetés.” [In: SCHWARTZ, 1955, p.147]
}

5 ANDRADE, Oswald, In: SCHWARTZ, 1955, p.142.

6 In: SCHWARTZ, 1955, p.553. 
Já Mario de Andrade em 1928 (ano da também manifestação antropofágica de Oswald) traz à tona a idéia da busca das raízes da nacionalidade brasileira através da literatura com a história do personagem Macunaíma - herói brasileiro sem nenhum caráter, um homem negro que nasce com idade já avançada em uma tribo indígena:

No fundo do mato-virgem nasceu Macunaíma, herói de nossa gente. Era preto retinto e filho do medo da noite. Houve um momento em que o silêncio foi tão grande escutando o murmurejo do Uraricoera, que a índia tapanhumas pariu uma criança feia. [ANDRADE, 2004, p. 13]

Com esse livro, Andrade além de desconstruir a retórica lingüística vigente em literatura na época, aproximando a escrita ao modo de falar do brasileiro, também traçou ficcionalmente uma linha de pensamento para pensarmos na própria questão do homem nacional. Elucida a história de um personagem típico brasileiro, trazendo a tona palavras de uma cultura esquecida, num país que ainda contém diversos nomes indígenas denominando ruas e bairros, e tenta de um modo "inocente" catequizar os que lêem, com frases que distinguem nossa própria terra:

Macunaíma ia seguindo e topou com a árvore Volomã bem alta. Num galho estava um pitiguari que nem bem enxergou o herói, se desgoelou cantando - "Olha no caminho quem vem! Olha no caminho quem vem!" Macunaíma olhou pra cima com intenção de agradecer mas Volomã estava cheinha de fruta. O herói vinha dando horas de tanta fome e a barriga dele empacou espiando aquelas sapotas sapotilhas sapotis bacuris abricós mucajás miritis guabijus melancias ariticuns, todas essas frutas. [ANDRADE, 2004, p.65]

Seu personagem vive fatos irreais na mata brasileira, depois muda-se para São Paulo para tentar se civilizar na cidade grande e acredita que os males do Brasil são muita saúva e pouca saúde, tudo isso permeando uma mescla de atualização as crenças indígenas de raiz, do pensamento de um personagem acúmulo de conceitos sobre o cidadão brasileiro e de modo irreverente tenta não distanciar das questões do próprio povo; assim Mario de Andrade na brincadeira poética acredita: "Se somando isso com minha preocupação brasileira profundamente pura, temos Macunaíma, livro meu."

7 ANDRADE, Mario In: SCHWARTZ, 1955, p.552. 
Tanto em Holanda como em Mario de Andrade vemos manifestações para entender essa raiz e o labirinto que se encontram a nacionalidade brasileira postuladas aqui por duas vertentes: uma historiográfica e outra literária. Sabe-se que a identidade nacional brasileira é tão fictícia quanto a criação de um personagem como Macunaíma, ou tão inventiva como a busca de uma historiografia geral para entender nossas raízes. Oswald, Mario de Andrade e seus parceiros de pensamento estético moderno em arte sabiam disso.

Armando então um traço histórico para analisar o personagem brasileiro e construindo literatura para achar a raiz no parentesco tribal, a primeira vanguarda artística brasileira da as caras e toma a frente do circuito cultural como um pelotão de frente de um exército mostra também sua avant garde ${ }^{8}$.

Nas obras de Tarsila do Amaral, encontramos a exemplificação conjunta dessas idéias vanguardista brasileira. Além da temática nacionalista que permeava seus quadros, como o cotidiano brasileiro, paisagens, vida na cidade e figurações alusões à raiz indígena, Tarsila empregava cores vibrantes como verde bandeira e o amarelo forte para reforçar o caráter nacionalista, deixando transparecer sua nova técnica pictórica apreendida em sua estada em Paris quando entrou em contato com a vanguarda européia. Assim seguiram alguns artistas na valorização desse projeto estético nacional, como Anita Malfatti, que apesar da crítica da época não ter processado o fato inovador, como qualquer primeiro embate que se há com o novo, seguiram até décadas seguintes com a vontade de perdurar a legitimação brasileira.

Por consequiência, havia assim uma herança deixada dos primeiros modernistas brasileiros para as manifestações em arte seguintes a semana de 22. O Concretismo brasileiro surgido nos anos 50, assim como o Neoconcretismo nos anos 60 e seus desdobramentos nas décadas seguintes, consolidaram também um modo inovador de produzir arte no país. ${ }^{9}$

8 Em seu sentido literal, vanguarda (que vem do francês Avant Garde, "guarda avante") faz referência ao batalhão militar que precede as tropas em ataque durante uma batalha. Daí deduz-se que vanguarda é aquilo que "está à frente".

9 Dois movimentos de concepção altamente nacionais: pelo novo código construtivo dos artistas de São Paulo e principalmente pela vertente do Rio de Janeiro com Hélio Oiticica, Lygia Clark, Lygia Pape e outros, onde se criou uma nova concepção de arte. "O neoconcretismo estabeleceu a crise da representação no plano bidimensional e um novo estatuto da obra de arte. [...] mas foi no texto 'teorias do não-objeto', de Ferreira Gullar, [...] que um olhar mais amplo sobre as pesquisas poéticas dos artistas neoconcretos e um anuncio da questão do objeto forma vitais para se entender os anos 60 na arte brasileira e suas relações com a sociedade. [...] O objeto trazia, implicitamente, uma nova posição do espectador no acionamento de seus significados e a 'participação do espectador na obra de arte' [...]' In: REIS, Paulo R. O. Arte de Vanguarda no Brasil: os anos 60. RJ. Jorge Zahar Ed. 2006. 
Todo o pensamento sobre as questões estéticas dentro do país em fim dos anos 60, por exemplo, voltou-se para dialogar com o sistema do próprio país, do regime ditatorial que aqui se instalava. E ainda assim, como na ruptura modernista de 1920, os movimentos vanguardistas seguintes em geral carregavam a premissa de uma arte elucidativa, explicativa. Seus representantes criavam as concepções de base, discutiam e escreviam sobre seus ideais e não as deixam de publicar em um jornal de grande circulação. ${ }^{10}$

Havia a vontade vanguardista de legitimação da arte que surgia. Havia essa vontade assim como encontramos o anseio de legitimação na busca das raízes desse país ainda não inventado, recriado pelos primeiros modernistas.

E o que legitima a arte produzida hoje?

$\mathrm{Na}$ fusão de idéias contemporâneas, no aparecimento gradativo de novos artistas, na globalização exacerbada de informações a atual arte brasileira, e de um modo geral, encontrase em tal ponto que o próprio circuito de arte está acanhado em dar seu parecer certeiro sobre a legitimidade dessas obras produzidas. Não temos mais as manifestações ferrenhas de um novo sistema que surge, não temos mais a linha tênue do percurso moderno que seguiam os artistas.

A figura da manifestação em relação a uma idéia desapareceu. Estamos num momento suspensos por estagnação enfática, não que as produções tenham se cessado, mas o que cessou foram a liberdade e a coragem de dar o parecer sobre. A mudança desse sistema cultural é comentada por Luciano Trigo no seu texto "A Falência da crítica de arte" que de um modo geral fala sobre a estagnação dessa legitimação e a imposição da mercantilização na arte hoje. Trigo cita que tanto para o artista quanto para o crítico hoje é mais importante essa rede de relacionamentos e cumplicidade que mantém em jogo a arte no circuito, do que a própria relação com a arte em si, refletindo assim esse processo exacerbado que é o emprego do mercado financeiro na esfera artística.

10 Com relação ao movimento Concreto de 1950-60: "Os membros assinaram e distribuíram para o público da exposição o Manifesto Ruptura, que continha, no formato de palavras de ordem e com o projeto gráfico concreto (estruturado segundo a Gestalt visual), a idéia de que a arte do passado estava em crise e que eles eram a renovação [...] a exposição gerou diversas discussões no meio cultural brasileiro. Sérgio Millet criticou o grupo publicamente no jornal O Estado de S. Paulo, e Waldemar Cordeiro respondeu às críticas no Correio Paulistano. Começavam aí uma série de polêmicas em jornais e revistas que se estendiam por toda a década de 50". Tatiana Rysevas Guerra (2007) 
Com o decreto do pós-moderno do fim das grandes narrativas, os artistas perderam essa ambição de abrangência e passaram a se movimentar de forma errática, seguindo os fluxos do mercado com seus comentários neutros e modestos, caso a caso. Com isso se dissolveu a base para qualquer interpretação consistente da arte contemporânea. Em que valores se pode basear o julgamento de um cubo de chocolate ou de uma mesa de pingue-pongue coberta de cascas de ovos? [TRIGO, 2008]

Claro que quando Trigo cita: “Apático e descafeinado, o crítico passou a duvidar da própria autoridade" ${ }^{11}$, ele mantém uma visão saudosista da idéia do crítico de arte ser visto como formador de opiniões absolutas e concisas. Além disso, ainda desenvolve uma reflexão sobre o caráter literário que a crítica de arte perdeu, como o estilo próprio da escrita e a capacidade de persuasão que detinha, podendo citar aqui as manifestações nacionais de Mario de Andrade e Monteiro Lobato, assim o autor afirma: “Hoje o crítico não está preocupado em atingir uma grande audiência, nem escreve mais para o leitor, mas para seus pares e para os outros agentes do sistema da arte - ou do sistema acadêmico, no caso dos textos universitários - que, no Brasil, nunca se caracterizaram pela clareza" ${ }^{12}$. Talvez com essa relação de clareza ao qual cita, Trigo possa estar se referindo a um momento moderno do purismo na obra, mas fato é que o modernismo não se baseava na mercantilização e sim num caráter de legitimar a identidade da obra.

Fato é que perdemos parte dessa utopia esperançosa vanguardista de construir um projeto estético em arte coerente com nossa cultura, ainda assimilamos o que nos é mostrado e parece que carecemos de um aceite exterior para nossa arte ser veiculada. Talvez o conceito da Antropofagia ainda não tenha nos deixado, entretanto está mascarado mais uma vez, como nos quatro séculos que antecederam a década de 20.

Ainda mais complexo é falar do problema no próprio turbilhão que é se encontrar dentro dele; só podemos então reconstruir a história novamente e pensar para onde nos encaminhamos.

11 TRIGO, 2008

12 TRIGO, 2008

DAPesquisa, Florianópolis, v.3 n.5, p.131-138, 2008. 


\section{Bibliografia}

ANDRADE, Mário. Macunaíma. (1928). RJ: Livraria Garnier. 2004.

ANDRADE, Oswald. Manifesto Antropófago. In: Revista de Antropofagia, Ano 1, № 1, maio de 1928.

HOLANDA, Sérgio Buarque de. (1936). Raízes do Brasil. SP: Companhia das Letras. 2006.

REIS, Paulo R. O. Arte de Vanguarda no Brasil: nos anos 60. RJ: Jorge Zahar Ed. 2006.

SCHWARTZ, Jorge. Vanguardas latino-americanas. Polêmicas, manifestos e textos críticos. SP: Iluminuras, EDUSP, FAPESP. 1955.

TRIGO, Luciano. (2008). A Falência da crítica. Disponível em:

< http://lucianotrigo.blogspot.com/2008/01/sobre-crtica-de-arte.html > Acessado em: 23 jul. 2008 ás $17 \mathrm{~h} 52 \mathrm{~min}$. 